\title{
Reaksi Investor dalam Pasar Modal Terhadap Penerbitan Perppu No. 1 Tahun 2017
}

\author{
I Gusti Ayu Ade Anggariani ${ }^{1}$ \\ I Gusti Ngurah Agung Suaryana ${ }^{2}$
}

\author{
${ }^{1}$ Fakultas Ekonomi dan Bisnis Universitas Udayana (Unud), Bali, Indonesia \\ email: ayuade420@yahoo.com / Telp.+6282 247985477 \\ ${ }^{2}$ Fakultas Ekonomi dan Bisnis Universitas Udayana (Unud), Bali, Indonesia
}

\begin{abstract}
ABSTRAK
Perppu Nomor 1 Tahun 2017 merupakan salah satu informasi yang dapat digunakan untuk menganalisis reaksi pasar. Tujuan penelitian ini untuk membuktikan secara empiris terdapatnya abnormal return dan trading volume activity yang signifikan di sekitar penerbitan Perppu Nomor 1 Tahun 2017. Penelitian ini adalah penelitian event study. Sampel yang digunakan adalah 42 perusahaan perbankan yang terdaftar di BEI dengan metode purposive sampling. Alat analisis yang digunakan adalah uji one sample t-test. Hasil penelitian menunjukkan bahwa terdapat abnormal return yang signifikan pada $t_{-1}$ dan $t_{+2}$, kemudian trading volume activity yang signifikan pada $t_{-2}, t_{-1}, t_{0}, t_{+1}, t_{+2}$. Kedepannya investor agar lebih mempertimbangkan informasi dari Perppu Nomor 1 Tahun 2017 pada saat penerapannya dilakukan di tahun 2018 untuk mengambil keputusan investasi agar memperoleh keuntungan.
\end{abstract}

Kata kunci: Event study, abnormal return, trading volume activity

\section{ABSTRACT}

Perppu Number 1/2017 is one of the information that can be used to analyze market reaction. The purpose of this research is to prove empirically the existence of abnormal return and trading volume activity significant around the bookkeeping Perppu Number 1/2017. This research is research event study. The sample used 42 banking companies listed on the BEI with purposive sampling method. The analysis tool used is one sample t-test. The results showed that there was significant abnormal return at $t_{-1}$ and $t_{+2}$, then trading volume activity volume was significant at $t_{-2}, t_{-1}, t_{0}, t_{+1}, t_{+2}$. In the future, investors should consider information from Perppu Number 1/2017 when the application is done in 2018 to make investment decisions in order to gain profit.

Keyword: Event study, abnormal return, trading volume activity

\section{PENDAHULUAN}

Pasar modal adalah pertemuan antara pihak yang memiliki kelebihan dana dengan pihak yang membutuhkan dana dengan cara memperjualbelikan sekuritas (Tandelilin, 2010:26). Hal tersebut karena peran pasar modal sebagai sumber dana alternatif bagi kegiatan operasi perusahaan serta memberikan ruang bagi masyarakat dalam mengalokasikan dana yang dimilikinya untuk menghasilkan 
return melalui sektor-sektor yang produktif (Saputra, 2016). Menghasilkan return sangat erat hubungannya dengan naik turunnya harga saham.

Perkembangan harga saham adalah indikator bagi investor untuk mengetahui perilaku pasar. Perilaku pasar terjadi didorong oleh suatu informasi dalam suatu pengumuman baik dari lingkungan dalam (internal) maupun luar (eksternal) perusahaan. Informasi yang diumumkan dapat berupa peraturan pemerintah atau peraturan dari regulator yang hanya berdampak kepada hargaharga sekuritas perusahaan-perusahaan yang terkena regulasi tersebut.

Peraturan pemerintah terbaru yang telah diterbitkan pada tanggal 8 Mei 2017 yaitu penerbitan Peraturan Pemerintah Pengganti Undang-Undang (Perppu) Nomor 1 Tahun 2017 merupakan salah satu informasi yang dapat diserap oleh para investor di pasar modal dan digunakan untuk menganalisis keadaan atau reaksi pasar. Penerbitan Perppu Nomor 1 Tahun 2017 mengatur tentang Akses Informasi Keuangan untuk Kepentingan Perpajakan. Tujuan dari menerbitkan Perppu ini karena Indonesia telah mengikatkan diri pada perjanjian internasional di bidang perpajakan yang berkewajiban untuk memenuhi komitmen keikutsertaan dalam mengimplementasikan pertukaran informasi keuangan secara otomatis (Automatic Exchange of Financial Account Information) (www.peraturan.go.id, 2017).

Perppu ini cenderung berdampak ke lembaga jasa keuangan yang berkewajiban menyampaikan laporan berisi informasi keuangan kepada Direktur Jenderal Pajak. Lembaga jasa keuangan yang wajib menyampaikan laporan salah satunya yaitu perusahaan perbankan. Bank adalah suatu lembaga yang hidupnya 
tergantung dari dana masyarakat yang disimpan pada bank. Masyarakat bersedia menyimpan dananya kepada bank maka, masyarakat harus memiliki kepercayaan bahwa bank menjamin kerahasiaan atas semua data-datanya (Towoliu, 2013).

Dampak negatif yang dapat timbul dari penerapan perppu ini yaitu akan terjadinya penarikan dana oleh nasabah orang pribadi yang memiliki jumlah saldo paling sedikit yaitu satu milyar dan bagi entitas tidak terdapat batasan saldo (Kementerian Keuangan, 2017). Hal tersebut akan menimbulkan tingkat likuiditas perbankan akan menurun. Nasabah yang merasa belum menjalankan kewajiban perpajakannya akan mengalihkan dananya keluar negeri, sehingga terjadinya capital outflow yang akan menganggu likuiditas perbankan. Menurut Ryan Kiryanto Sekretaris Perusahaan BNI, dampak positif penerbitan Perppu ini yaitu perusahaan perbankan akan lebih menjunjung nilai-nilai disiplin pasar dan tata kelola perusahaan yang baik. Alhasil, industri perbankan nasional bakal lebih sehat, kredibel dan siap dalam menghadapi berbagai kondisi dan risiko dalam penerapan Perppu ini (www.beritasatu.com, 2017).

Dampak positif ini dapat mempengaruhi investor untuk berinvestasi karena perusahaan perbankan berpotensi akan meningkatkan likuiditas perusahaan yang sangat membantu bagi manajemen untuk mengecek efisiensi modal kerja yang digunakan dan juga penting bagi pemegang saham yang ingin mengetahui prospek dari dividen di masa datang (Munawir, 1998:71). 


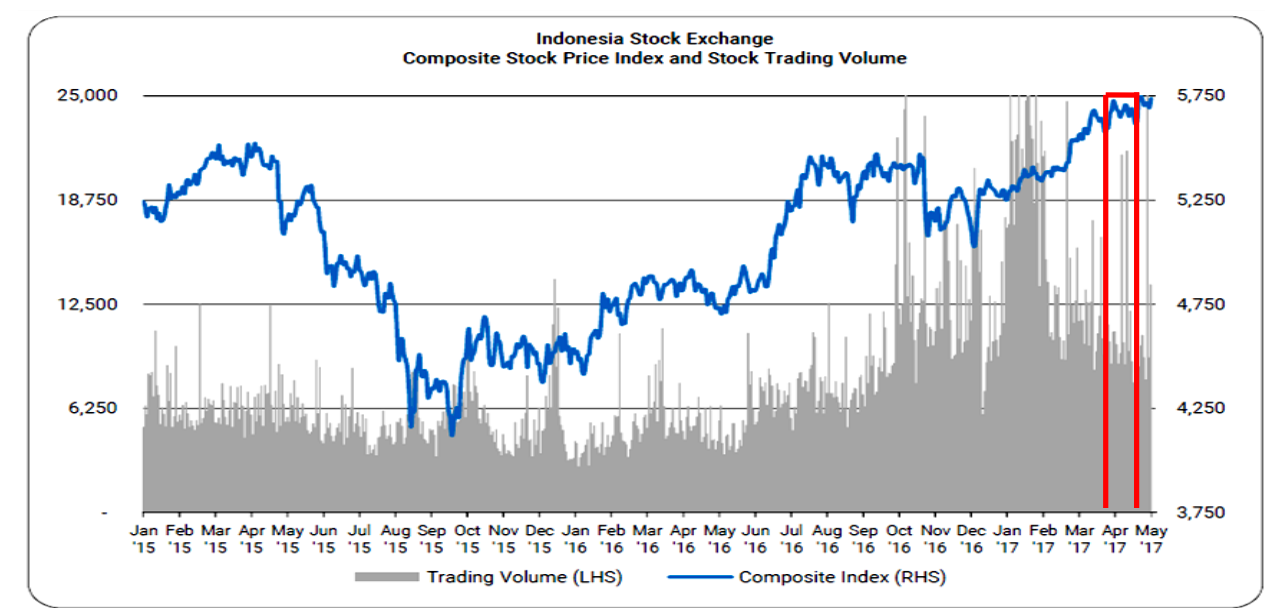

Gambar 1.
Grafik Indeks Harga Saham Gabungan Januari 2015 - Mei 2017

Sumber: www.idx.co.id, 2017

IHSG pada bulan Mei 2017, diterbikannya peraturan tersebut mengalami kecenderungan peningkatan yang tinggi dibuktikan pada gambar diatas. IHSG mencerminkan perubahan harga saham secara umum pada akhirnya mencapai rekor tertinggi (Sanjiwani \& Jati, 2017). Pada bulan Mei 2017 IHSG ditutup menguat sebesar $0,93 \%$. Sejumlah saham perbankan yang termasuk dalam saham likuid, seperti Bank Central Asia Tbk (BBCA), Bank Negara Indonesia (Persero) Tbk (BBNI), Bank Rakyat Indonesia (Persero) Tbk (BBRI) dan Bank Mandiri (Persero) Tbk (BMRI) pada tanggal 8 Mei 2017 mengalami peningkatan harga saham dan volume perdagangan saham.

Saham BBCA dibuka di level Rp17.775 ditutup naik ke posisi Rp17.950, BBNI dari Rp6.575 ke Rp6.725, BBRI dari Rp13.925 ke Rp14.100 dan BMRI dari Rp11.975 ke Rp12.050. Melihat beberapa saham perbankan mengalami kenaikan tersebut, ada juga penurunan harga saham dan penurunan volume perdagangan saham. Melihat data IHSG, perubahan harga saham dan volume 
perdagangan saham diatas memberikan keyakinan bagi peneliti bahwa penerbitan Perppu No. 1 Tahun 2017 mempengaruhi reaksi pasar.

Konsep efisiensi pasar membahas bagaimana pasar merespons informasiinformasi yang masuk, dan bagaimana informasi tersebut selanjutnya bisa mempengaruhi pergerakan harga sekuritas menuju harga keseimbangan yang baru (Tandelilin, 2010:218). Salah satu asumsi penting adalah bahwa pasar modal cukup efisien untuk bereaksi terhadap kejadian (informasi baru) mengenai keuntungan masa depan yang diharapkan dari perusahaan yang terkena dampaknya (Repousis, 2016). Menurut hipotesis pasar yang efisien (EMH), harga aset mencerminkan datangnya informasi baru dengan cepat (Vikash, Moosa, \& Nguyen, 2017). Fama (1970) menyajikan tiga macam bentuk utama dari efisiensi pasar, yaitu efisiensi pasar bentuk lemah (weak form), efisiensi pasar bentuk setengah kuat (semistrong form), dan efisiensi pasar bentuk kuat (strong form). Pengujian efisien pasar bentuk setengah kuat adalah studi peristiwa (event studies), yaitu harga mencerminkan semua informasi publik yang relevan Fama (1991).

Studi peristiwa (event study) merupakan studi yang mempelajari reaksi pasar terhadap suatu peristiwa (event) yang informasinya dipublikasikan sebagai suatu pengumuman (Hartono, 2015:624). Event study melibatkan estimasi return normal untuk keamanan dan menghitung arah dan ukuran kelebihan return yang diakibatkan oleh informasi yang tidak diantisipasi (Hall \& Kenjegaliev, 2016). Gul et al. (2013) menunjukkan bahwa peristiwa memiliki dampak yang signifikan terhadap harga saham. Indikator untuk mengukur adanya reaksi pasar dapat dilihat 
I Gusti Ayu Ade Anggariani dan I Gusti Ngurah Agung Suaryana. Reaksi...

dari abnormal return yang diperoleh investor. Apabila terdapat abnormal return di sekitar penerbitan Perppu No. 1 Tahun 2017 menandakan bahwa pasar bereaksi terhadap informasi tersebut.

Sejalan dengan penelitian pada Peristiwa non ekonomi bom JW Mariott/Ritz Carlton pada tanggal 17 juli 2009 menghasilkan abnormal return bagi investor (Hidayat, 2012). Pengumuman lainnya yaitu pengumuman paket kebijakan ekonomi tahap I Jokowi-JK menghasilkan abnormal return positif signifikan di sekitar terjadinya peristiwa tersebut (Wibowo, 2017). Penelitian internasional yang sejalan dengan hasil penelitian diatas juga dilakukan oleh Makino (2016), meneliti respon pasar saham terhadap kecelakaan kimia di Jepang menghasilkan abnormal return rata-rata kumulatif negatif secara signifikan setelah terjadinya kecelakaan tersebut.

Hasil yang sama juga ditemukan oleh Xiao \& Gao (2017) bahwa terdapat abnormal return yang signifikan pada tanggal kejadian proses legislatif UndangUndang tentang Keamanan Pangan pada industri makanan di China. Li et al. (2016) menghasilkan cumulative abnormal return dan cumulative average abnormal return negatif yang signifikan pada saat bencana alam dan tingkat kecelakaan produksi terjadi di pasar saham China. Hachenberg et al. (2016) dalam penelitiannya tentang dampak dari hasil pemilihan presiden A.S yaitu Donald Trump pada tahun 2016 dan perubahan peraturan yang berdampak kepada sektor keuangan menghasilkan average abnormal return positif. Asteriou et al. (2013) melakukan penelitian terhadap pengumuman besar seperti pengumuman Olimpiade London 2012 dimana menghasilkan abnormal return yang positif dan 
signifikan pada beberapa indutri di London Stock Exchange. Begitu pula dengan penelitian Abuzayed (2013) menghasilkan abnormal return positif dan signifikan terhadap pengumuman Piala Dunia 2022 pada bursa saham Negara yang dinominasikan.

Sebaliknya, beberapa penelitian tidak menemukan abnormal return signifkan, seperti penelitian Sudewa P \& Sari (2015) atas peristiwa pilpres 2014. Penelitian dari Pratama, dkk. (2015) tidak menemukan hasil abnormal return yang signifikan pada peristiwa pelantikan Joko Widodo sebagai Presiden RI ke-7. Repousis (2016) menyatakan bahwa terdapat abnormal return cumulative yang tidak signifikan di sekitar tanggal kejadian krisis perbankan Cypriot. Danylchuk et al. (2016) dalam penelitiannya juga tidak menemukan abnormal return yang signifikan dari dampak skandal doping dalam acara Grand Tour bersepeda professional pada saham sponsor tim utama. Berdasarkan uraian tentang abnormal return, maka hipotesis yang dikembangkan dalam penelitian ini adalah:

$\mathrm{H}_{1}$ : Terdapat abnormal return yang signifikan di sekitar penerbitan Perppu No. 1 Tahun 2017.

Reaksi pasar modal terhadap suatu informasi dapat dilihat dengan trading volume activity selain melihat abnormal return. Trading volume activity adalah alat untuk mengamati reaksi pasar modal melalui pergerakan volume perdagangan pada saat pasar modal tersebut diteliti (Yuwono, 2013). Perhitungan trading volume activity yaitu dengan membandingkan jumlah saham perusahaan yang diperdagangkan dengan keseluruhan jumlah saham beredar perusahaan selama periode penelitian (Yuniati, 2017). Apabila terdapat trading volume activity di 
I Gusti Ayu Ade Anggariani dan I Gusti Ngurah Agung Suaryana. Reaksi...

sekitar penerbitan Perppu No 1 Tahun 2017 berarti informasi tersebut mempengaruhi investor melakukan transaksi jual beli saham.

Saputra (2016) dalam penelitiannya menemukan trading volume activity yang signifikan pada peristiwa pemilihan umum presiden dan wakil presiden tahun 2014 saham LQ-45. Penelitian tentang pengumuman kenaikan harga BBM awal pemerintahan Jokowi-JK juga menemukan adanya trading volume activity saat hari peristiwa hingga lima hari setelah peristiwa (Febriyanti \& Rahyuda, 2016). Penelitian Wulandari, dkk. (2017) menemukan trading volume activity yang signifikan setelah terjadinya peristiwa berlakunya undang-undang tax amnesty. Penelitian Tila, dkk (2017) menemukan bahwa terdapat trading volume activity yang signifikan pada saat Pilpres Amerika Serikat 2016.

Hasil yang sama juga diperoleh dari penelitian internasional. De Souza et al. (2017) meneliti hubungan proxy efek perhatian investor, liputan media dan volume perdagangan pasar saham Brazil yang menghasilkan volume perdagangan yang signifikan yang dipengaruhi oleh berita pada hari-hari baik. Rosati et al. (2017) dalam penelitiannya menghasilkan volume perdagangan yang signifikan pada hari pengumuman pelanggaran data sebagai sumber informasi asimetris yang pontensial dan memberikan dimensi baru pada perdebatan mengenai efisiensi pasar. Zhang et al. (2013) meneliti dampak media terhadap return saham di China dan menemukan terdapat volume perdagangan saham yang signifkan membesar setelah berita diterbitkan. Sebaliknya, Purba (2017) melakukan penelitian pada peristiwa pemberlakuan PP No. 1 Tahun 2014 tentang larangan mengekspor mineral mentah dan hasilnya bahwa tidak ditemukannya trading volume activity 
yang signifikan. Berdasarkan uraian tentang trading volume activity, maka hipotesis yang dikembangkan dalam penelitian ini adalah:

$\mathrm{H}_{2}$ : Terdapat trading volume activity yang signifikan di sekitar penerbitan Perppu No. 1 Tahun 2017.

\section{METODE PENELITIAN}

Penelitian ini adalah penelitian event study. Peristiwa yang diuji dalam penelitian ini adalah peristiwa penerbitan Perppu Nomor 1 Tahun 2017. Informasi dari penerbitan Perppu Nomor 1 Tahun 2017 akan diuji terhadap reaksi investor dalam pasar modal yang diproksikan dengan abnormal return dan trading volume activity pada saham-saham perusahaan perbankan. Adapun desain penelitian ini disajikan sebagai berikut:

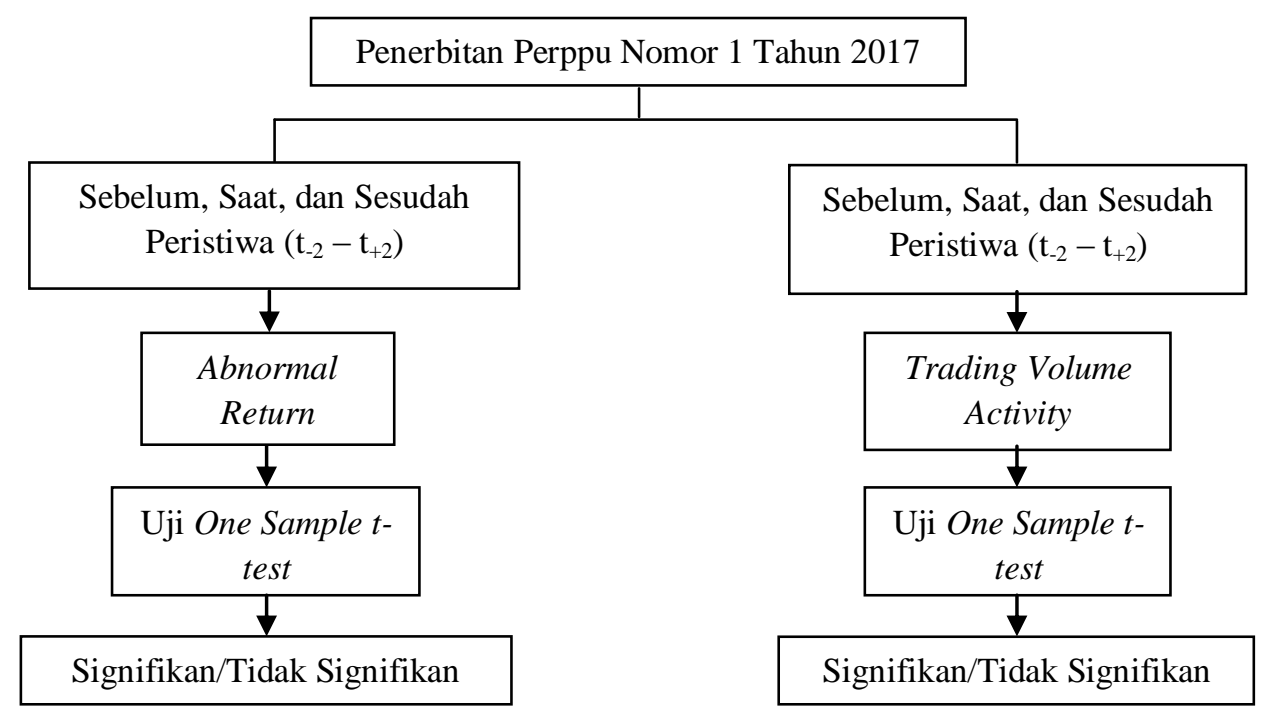

Gambar 2.Desain Penelitian

Sumber: Data diolah, 2017

Lokasi penelitian dilakukan di Bursa Efek Indonesia pada perusahaan perbankan dengan mengakses website www.idx.co.id. Objek dari penelitian ini adalah reaksi investor dalam pasar modal dari pengumuman Penerbitan Perppu 
I Gusti Ayu Ade Anggariani dan I Gusti Ngurah Agung Suaryana. Reaksi...

No. 1 Tahun 2017 di Bursa Efek Indonesia. Reaksi pasar diukur dengan menggunakan abnormal return dan trading volume activity.

Abnormal return adalah kelebihan dari return yang sesungguhnya terjadi terhadap return ekspektasian (return yang diharapkan oleh investor). Return tak normal (abnormal return) adalah selisih antara return sesungguhnya yang terjadi dengan return ekspektasian (Hartono, 2015:647). Langkah-langkah untuk mencari abnormal return, yaitu sebagai berikut:

1) Menghitung return sesungguhnya atau return realisasian yang dapat dihitung dengan rumus (Hartono, 2015:648):

$\mathrm{R}_{\mathrm{i}, \mathrm{t}}=\frac{\mathrm{P}_{\mathrm{i}, \mathrm{t}}-\mathrm{P}_{\mathrm{i}, \mathrm{t}-1}}{\mathrm{P}_{\mathrm{i}, \mathrm{t}-1}}$

Keterangan:

$\mathrm{R}_{\mathrm{i}, \mathrm{t}} \quad=$ return saham $\mathrm{i}$ pada periode ke- $\mathrm{t}$

$\mathrm{P}_{\mathrm{i}, \mathrm{t}} \quad=$ harga saham penutupan perusahaan i pada periode ke- $\mathrm{t}$

$\mathrm{P}_{\mathrm{i}, \mathrm{t}-1}=$ harga saham penutupan perusahaan i pada periode ke-t-1

2) Menghitung return ekspektasian (expected return) menggunakan model mean-adjusted model dengan periode estimasi 200 hari (Hartono, 2015:659). Dirumuskan sebagai berikut:

$\mathrm{E}\left[\mathrm{R}_{\mathrm{i}, \mathrm{t}}\right]=\sum \frac{\mathrm{Rit}}{\mathrm{T}}$

Keterangan:

$\mathrm{E}\left[\mathrm{R}_{\mathrm{i}, \mathrm{t}}\right]=$ return ekspektasian sekuritas ke-i untuk periode peristiwa ke- $\mathrm{t}$

$\mathrm{R}_{\mathrm{i}, \mathrm{t}}=$ return realisasian yang terjadi untuk sekuritas ke-i pada periode estimasi ke-t

$\mathrm{T} \quad=$ lamanya periode estimasi

3) Menghitung abnormal return yang dirumuskan sebagai berikut (Hartono, 2015:647):

$\mathrm{RTN}_{\mathrm{i}, \mathrm{t}}=\mathrm{R}_{\mathrm{i}, \mathrm{t}}-\mathrm{E}\left[\mathrm{R}_{\mathrm{i}, \mathrm{t}}\right]$ 
Keterangan:

$\mathrm{RTN}_{\mathrm{i}, \mathrm{t}}=$ return tak normal (abnormal return) sekuritas ke-i pada periode peristiwa ke-t

$\mathrm{R}_{\mathrm{i}, \mathrm{t}} \quad=$ return realisasian yang terjadi untuk sekuritas ke-i pada periode peristiwa ke-t

$\mathrm{E}\left[\mathrm{R}_{\mathrm{i}, \mathrm{t}}\right]=$ return ekspektasian sekuritas ke-i untuk periode peristiwa ke- $\mathrm{t}$

4) Menghitung rata-rata abnormal return (average abnormal return) untuk tiap-tiap hari di periode peristiwa, dapat dihitung dengan rumus sebagai berikut (Hartono, 2015:660):

$\operatorname{RRTN}_{\mathrm{t}}=\frac{\sum_{\mathrm{i}=1}^{\mathrm{k}} \operatorname{RTN}_{\mathrm{i}, \mathrm{t}}}{\mathrm{k}}$

Keterangan:

$\mathrm{RRTN}_{\mathrm{t}}=$ rata-rata return tak normal (average abnormal return) pada hari ke-t

$\mathrm{RTN}_{\mathrm{i}, \mathrm{t}}=$ return tak normal (abnormal return) untuk sekuritas ke-i pada hari ke-t

$\mathrm{k} \quad=$ jumlah sekuritas yang terpengaruh oleh pengumuman peristiwa

Trading volume activity adalah alat untuk mengamati reaksi pasar modal melalui pergerakan volume perdagangan pada saat pasar modal tersebut diteliti (Yuwono, 2013). Menurut Ang (1997) menjelaskan bahwa perkembangan volume perdagangan saham mencerminkan kekuatan antara penawaran dan permintaan yang merupakan cerminan dari tingkah laku investor. Perhitungan TVA sebagai berikut (Suryawijaya dan Setiawan, 1998 dalam Febriyanti \& Rahyuda, 2016):

1) Perhitungan TVA masing-masing saham selama periode penelitian dirumuskan sebagai berikut:

$\mathrm{TVA}_{\mathrm{i}, \mathrm{t}}=\frac{\sum \text { saham perusahaan } \mathrm{i} \text { yang diperdagangkan pada waktu ke } \mathrm{t}}{\sum \text { saham perusahaan i yang beredar pada waktu ke } \mathrm{t}}$

Keterangan:

$\mathrm{TVA}_{\mathrm{i}, \mathrm{t}}=$ trading volume activity untuk sekuritas ke-i pada hari ke- $\mathrm{t}$ 
2) Menghitung average trading volume activity (ATVA) seluruh saham per hari selama periode peristiwa, yaitu:

$\operatorname{ATVA}_{\mathrm{t}}=\frac{\sum_{i=1}^{n} \operatorname{TVA}_{\mathrm{i}, \mathrm{t}}}{\mathrm{n}}$

Keterangan:

$\mathrm{ATVA}_{\mathrm{t}}=$ average trading volume activity pada hari ke-t

$\mathrm{TVA}_{\mathrm{i}, \mathrm{t}}=$ trading volume activity untuk sekuritas ke-i pada hari ke-t

$\mathrm{n} \quad=$ jumlah sekuritas

Tanggal suatu peristiwa dipublikasikan untuk pertama kali ditetapkan sebagai event day $\left(\mathrm{t}_{0}\right)$ (Yuniati, 2017). Event day dari penerbitan Perppu Nomor 1 Tahun 2017 adalah hari Senin pada tanggal 8 Mei 2017. Periode peristiwa yang digunakan adalah 5 hari bursa, yaitu 2 hari sebelum penerbitan $\left(\mathrm{t}_{-2}\right)$ untuk mengetahui apakah terjadi kebocoran informasi, 1 hari saat penerbitan (event date, $\left.\mathrm{t}_{0}\right)$ untuk mengetahui reaksi pasar, dan 2 hari sesudah tanggal penerbitan $\left(\mathrm{t}_{+2}\right)$ untuk mengetahui kecepatan reaksi pasar yang terjadi.

Menurut Dai et al. (2013), event period yang lebih pendek dapat menunjukkan pola yang lebih signifikan. Hartono (2015:649) menjelaskan bahwa suatu periode jendela yang pendek diambil karena investor akan bereaksi dengan cepat terhadap peristiwa yang diprediksi memiliki nilai ekonomis. Periode jendela dalam penelitian ini dapat dilihat pada gambar berikut:

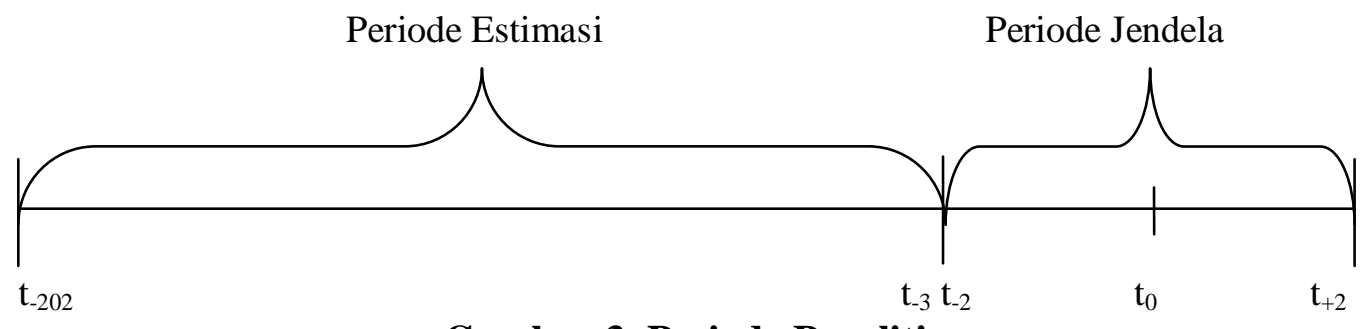

Sumber: Data diolah, 2017 
Menurut Sugiyono (2013:115), populasi adalah wilayah generalisasi yang terdiri atas objek atau subjek yang mempunyai kualitas dan karakteristik tertentu yang ditetapkan oleh peneliti. Populasi dalam penelitian ini adalah saham-saham perusahaan perbankan yang terdaftar dalam Bursa Efek Indonesia karena secara khusus penelitian ini meneliti reaksi pasar pada peristiwa Perppu Nomor 1 Tahun 2017 dimana mengatur lembaga jasa keuangan salah satunya, yaitu perusahaan perbankan. Perusahaan perbankan sangat memperhatikan kepercayaan masyarakat dalam menarik masyarakat untuk menyimpan uangnya di bank, maka kerahasiaan data-data nasabah sangat penting dijaga.

Sampel adalah bagian dari jumlah karakteristik yang dimiliki oleh populasi tersebut (Sugiyono, 2013:115). Metode penentuan sampel yang digunakan adalah metode nonprobability sampling dengan menggunakan teknik purposive sampling. Purposive sampling adalah metode penentuan sampel dengan pertimbangan-pertimbangan tertentu sehingga sampel yang dibentuk dapat mewakili sifat-sifat populasi (Sugiyono, 2013:122). Pengambilan sampel dalam penelitian ini didasarkan atas pertimbangan, yaitu perusahaan yang masuk dalam perusahaan perbankan periode 2016-2017 di Bursa Efek Indonesia dan tidak melaksanakan corporate action pada periode pengamatan agar terhindar dari confounding effect. Corporate action yaitu stock split, pengumuman dividen, right issue, saham bonus dan penerbitan warrant.

Berdasarkan kriteria pemilihan sampel, diperoleh jumlah sampel sebanyak 42 perusahaan perbankan yang dapat dilihat pada tabel berikut: 
Tabel 1.

Hasil Pemilihan Sampel

\begin{tabular}{clc}
\hline No & \multicolumn{1}{c}{ Kriteria } & Jumlah Perusahaan \\
\hline 1 & $\begin{array}{l}\text { Saham perusahaan perbankan yang tercatat di Bursa } \\
\text { Efek Indonesia pada periode 2016-2017 }\end{array}$ & 43 \\
& $\begin{array}{l}\text { Saham perusahaan perbankan yaitu Bank Permata } \\
\text { Tbk melakukan corporate action yaitu pengumuman } \\
\text { right issue pada periode pengamatan }\end{array}$ & Jumlah Sampel Akhir \\
\hline \multicolumn{2}{c}{ Sumber: Data diolah, 2017} & 42 \\
\hline
\end{tabular}

Berdasarkan tabel 1, diketahui bahwa jumlah populasi pada penelitian yaitu sebanyak 43 perusahaan perbankan yang terdaftar di Bursa Efek Indonesia, namun terdapat 1 perusahaan yang melakukan corporate action yaitu Bank Permata Tbk yang melakukan pengumuman right issue pada periode pengamatan sehingga dikeluarkan dari sampel penelitian.

Metode pengumpulan data yang digunakan adalah metode observasi non partisipan. Penelitian ini menggunakan data kuantitatif dan data kualitatif. Data yang dibutuhkan dalam penelitian ini, yaitu tanggal penerbitan Perppu Nomor 1 Tahun 2017, daftar harga saham dan closing price untuk menghitung return sesungguhnya dan return ekspektasian periode jendela penelitian, volume perdagangan saham harian perusahaan dan jumlah saham yang beredar untuk menghitung trading volume activity periode jendela penelitian, dan nama-nama perusahaan perbankan yang terdaftar di Bursa Efek Indonesia periode 2016-2017.

Sumber data dalam penelitian ini adalah data sekunder yang diperoleh dari situs www.idx.co.id, Perppu Nomor 1 Tahun 2017, jurnal, literatur serta media lain yang mendukung penelitian ini. Teknik analisis data yang digunakan dalam penelitian ini yaitu uji one sample t-test. Pengujian analisis dalam penelitian ini menggunakan Microsoft Excel dan software SPSS 20. Pengambilan keputusan 
menggunakan tingkat kepercayaan 95\% atau $\alpha=5 \%$ dengan ketentuan, yaitu jika nilai signifikansi atau p-value $>0,05$, maka Ho diterima dan $\mathrm{H}_{1}$ ditolak dan jika nilai signifikansi atau p-value $\leq 0,05$, maka Ho ditolak dan $\mathrm{H}_{1}$ diterima (Ghozali, 2011:66). Sebelumnya diuji dengan statistik deskriptif dan uji normalitas terlebih dahulu.

\section{HASIL DAN PEMBAHASAN}

Deskriptif statistik merupakan bagian awal dari analisis data yang memberikan gambaran awal mengenai masing-masing variabel penelitian. Selama 5 hari perdagangan aktif periode pengamatan menghasilkan deskriptif statistik berupa nilai maksimum, nilai minimum, rata-rata (mean), dan standar deviasi variabel. Nilai minimum adalah nilai yang paling terendah dari suatu distribusi data, dan nilai maksimum adalah nilai yang paling tertinggi dari suatu distribusi data. Pengukuran rata-rata (mean) merupakan cara yang paling umum digunakan untuk mengukur nilai sentral dari suatu distribusi data. Standar deviasi variabel adalah ukuran-ukuran keragaman (variasi) data statistik yang paling sering digunakan. Adapun statistik deskriptif terhadap abnormal return ditunjukkan, sebagai berikut:

Tabel 2.

Deskriptif Statistik Abnormal Return

\begin{tabular}{ccccc}
\hline \multirow{2}{*}{\begin{tabular}{c}
\multirow{2}{*}{$\begin{array}{c}\text { Periode } \\
\text { Jendela }\end{array}$} \\
\cline { 2 - 5 }
\end{tabular}} & \multicolumn{2}{c}{$\begin{array}{c}\text { Pengumuman Penerbitan Perppu Nomor 1 Tahun 2017 Tentang } \\
\text { Informasi Keuangan untuk Kepentingan Perpajakan }\end{array}$} \\
\cline { 2 - 5 } & Minimum & Maksimum & Rata-rata & Standar Deviasi \\
\hline $\mathbf{- 2}$ & $-0,15214$ & 0,34704 & $-0,00189$ & 0,06652 \\
$\mathbf{- 1}$ & $-0,25188$ & 0,21204 & $-0,00087$ & 0,06543 \\
$\mathbf{0}$ & $-0,08450$ & 0,34588 & 0,01189 & 0,06451 \\
$\mathbf{+ 1}$ & $-0,04334$ & 0,23129 & 0,01775 & 0,06853 \\
$\mathbf{+ 2}$ & $-0,19361$ & 0,18528 & $-0,00868$ & 0,05110 \\
\hline
\end{tabular}

Sumber: Data diolah, 2017 
Hasil tabel 2 diketahui bahwa rata-rata selama 5 hari perdagangan pada tanggal 4 Mei 2017 sampai 10 Mei 2017 menghasilkan abnormal return yang positif terjadi pada hari $\mathrm{t}_{0}$ dan $\mathrm{t}_{+1}$, dimana itu berarti return realisasian lebih besar dari return yang diharapkan. Abnormal return yang negatif terjadi pada hari $\mathrm{t}_{-2}, \mathrm{t}_{-1}$ dan $\mathrm{t}_{+2}$, dimana itu berarti return realisasian lebih kecil dari return yang diharapkan.

Setelah melihat abnormal return, maka analisis deskriptif berikutnya pada aktivitas volume perdagangan. Hasil deskriptif statistik terhadap trading volume activity (TVA) ditunjukkan, sebagai berikut:

Tabel 3.

Deskriptif Statistik Trading Volume Activity (TVA)

\begin{tabular}{ccccc}
\hline \multirow{2}{*}{$\begin{array}{c}\text { Periode } \\
\text { Jendela }\end{array}$} & \multicolumn{3}{c}{$\begin{array}{c}\text { Pengumuman Penerbitan Perppu Nomor 1 Tahun 2017 Tentang } \\
\text { Informasi Keuangan untuk Kepentingan Perpajakan }\end{array}$} \\
\cline { 2 - 5 } & Minimum & Maksimum & Rata-rata & Standar Deviasi \\
\hline $\mathbf{- 2}$ & 0,00000 & 0,00814 & 0,00066 & 0,00133 \\
$\mathbf{- 1}$ & 0,00000 & 0,00989 & 0,00089 & 0,00189 \\
$\mathbf{0}$ & 0,00000 & 0,00286 & 0,00059 & 0,00079 \\
$\mathbf{+ 1}$ & 0,00000 & 0,00786 & 0,00090 & 0,00156 \\
$\mathbf{+ 2}$ & 0,00000 & 0,00732 & 0,00086 & 0,00161 \\
\hline
\end{tabular}

Sumber: Data diolah, 2017

Hasil tabel 3 dapat diketahui bahwa 2 hari sebelum, 1 hari saat dan 2 hari setelah pengumuman penerbitan Perppu Nomor 1 Tahun 2017 menunjukkan nilai ratarata yang berfluktuatif. Terlihat nilai minimum tertera 0,00000 yang berarti bahwa masih terdapat perusahaan yang tidak melakukan trade pada hari pengamatan.

Uji normalitas dalam penelitian ini menggunakan uji Kolmogorovsmirnov. Data dikatakan terdistribusi secara normal apabila nilai signifikansi dari Kolmogorov-smirnov test > 0,05 (Ghozali, 2011:34). Hasil uji normalitas dalam penelitian ini disajikan sebagai berikut: 
Tabel 4.

Pengujian Normalitas Data Abnormal Return

\begin{tabular}{ccc}
\hline \multirow{2}{*}{$\begin{array}{c}\text { Periode } \\
\text { Jendela }\end{array}$} & $\begin{array}{c}\text { Pengumuman Penerbitan Perppu Nomor 1 Tahun 2017 Tentang } \\
\text { Informasi Keuangan untuk Kepentingan Perpajakan }\end{array}$ \\
\cline { 2 - 3 } & Signifikansi (2-tailed) & Keterangan \\
\hline $\mathbf{- 2}$ & 0,112 & Normal \\
$\mathbf{- 1}$ & 0,092 & Normal \\
$\mathbf{0}$ & 0,777 & Normal \\
$\mathbf{+ 1}$ & 0,199 & Normal \\
$\mathbf{+ 2}$ & 0,072 & Normal \\
\hline
\end{tabular}

Sumber: Data diolah, 2017

Dari pengujian normalitas abnormal return pada tabel 4 terlihat bahwa sebelum, saat dan setelah pengumuman penerbitan Perppu Nomor 1 Tahun 2017 data terdistribusi normal. Terlihat bahwa tingkat signifikansi lebih dari 0,05 selama periode pengamatan. Hasil uji normalitas terhadap trading volume activity disajikan sebagai berikut:

Tabel 5.

Pengujian Data Trading Volume Activity (TVA)

\begin{tabular}{|c|c|c|}
\hline \multirow[t]{2}{*}{$\begin{array}{l}\text { Periode } \\
\text { Jendela }\end{array}$} & \multicolumn{2}{|c|}{$\begin{array}{c}\text { Pengumuman Penerbitan Perppu Nomor } 1 \text { Tahun } 2017 \\
\text { Tentang Informasi Keuangan untuk Kepentingan } \\
\text { Perpajakan }\end{array}$} \\
\hline & Signifikansi (2-tailed) & Keterangan \\
\hline-2 & 0,568 & Normal \\
\hline-1 & 0,529 & Normal \\
\hline $\mathbf{0}$ & 0,064 & Normal \\
\hline+1 & 0,143 & Normal \\
\hline+2 & 0,096 & Normal \\
\hline
\end{tabular}

Sumber: Data diolah, 2017

Pada tabel 5 terlihat bahwa semua data terdistribusi normal sebelum, saat dan setelah pengumuman penerbitan Perppu Nomor 1 Tahun 2017. Terlihat bahwa nilai signifikansi sudah menunjukkan lebih besar dari 0,05. Pengujian hipotesis dengan one sample t-test apabila sig (2-tailed) $<0,05$ maka terdapat abnormal return yang signifikan yang dapat diartikan juga ada reaksi pasar 
terhadap pengumuman penerbitan Perppu Nomor 1 Tahun 2017, begitu pula sebaliknya. Berikut hasil pengujiannya, yaitu:

Tabel 6.

Hasil Uji One Sample t-test Abnormal Return

\begin{tabular}{ccc}
\hline $\begin{array}{c}\text { Periode } \\
\text { Jendela }\end{array}$ & $\begin{array}{c}\text { Signifikansi } \\
\text { (2-tailed) }\end{array}$ & $\begin{array}{c}\text { Keterangan } \\
\text { Abnormal Return }\end{array}$ \\
\hline $\mathbf{- 2}$ & 0,855 & Tidak Terdapat \\
$\mathbf{- 1}$ & 0,009 & Terdapat \\
$\mathbf{0}$ & 0,239 & Tidak Terdapat \\
$\mathbf{+ 1}$ & 0,101 & Tidak Terdapat \\
$\mathbf{+ 2}$ & 0,009 & Terdapat \\
\hline
\end{tabular}

Sumber: Data diolah, 2017

Terlihat pada periode pengamatan terdapat abnormal return sebelum dan setelah pengumuman penerbitan Perppu Nomor 1 Tahun 2017 yang signifikan yaitu pada $t_{-1}$ dan $t_{+2}$. Nilai signifikansi pada $t_{-1}$ dan $t_{+2}$ menunjukkan hasil yang lebih kecil dari 0,05 yaitu sebesar 0,009. Berdasarkan analisis terhadap reaksi pasar yang diukur dengan abnormal return, hipotesis pertama yang menyatakan bahwa terdapat abnormal return yang signifikan di sekitar penerbitan Perppu No. 1 Tahun 2017 diterima. Perubahan rata-rata abnormal return dapat dilihat pada grafik berikut:

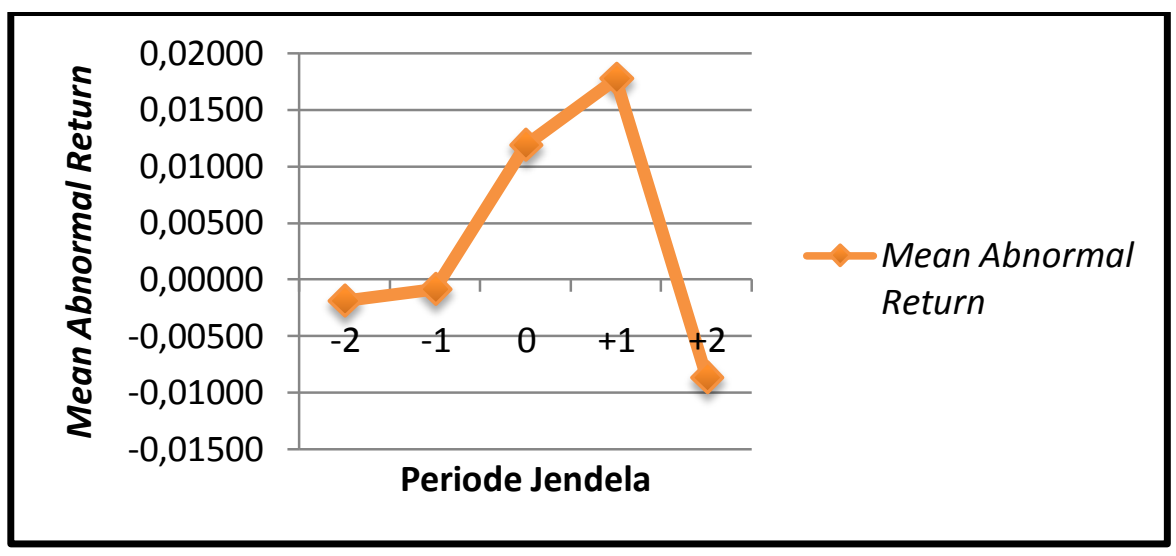

Gambar 4.

Perubahan Rata-Rata Abnormal Return Saham Periode Pengamatan Sumber: Data diolah, 2017 Penerbitan Perppu Nomor 1 Tahun 2017 
Berdasarkan grafik diatas menunjukkan adanya kebocoran informasi yang dapat dilihat dengan adanya reaksi sebelum pengumuman penerbitan Perppu yaitu pada $t_{-1}$. Kebocoran informasi tersebut menyebabkan beberapa investor bereaksi lebih awal untuk mendapatkan keuntungan yang tidak normal. Investor bereaksi lebih awal karena Perppu Nomor 1 Tahun 2017 sudah dipertimbangkan selama 15 tahun oleh pemerintah dan sebelum diundangkan Perppu ini harus mendapatkan persetujuan dari DPR terlebih dahulu. Abnormal return bernilai positif pada $t_{-1}$ (t-hitung sebesar 2,729), berarti reaksi awal investor menilai Perppu ini sebagai good news karena sebelum Perppu Nomor 1 Tahun 2017 diterbitkan, investor berpikir bahwa perlu adanya transparansi informasi keuangan untuk meningkatkan penerimaan pajak.

Setelah pengumuman penerbitan Perppu, adanya reaksi pada $t_{+2}$. Hal ini menunjukkan investor lambat bereaksi, sehingga tidak adanya reaksi yang diukur dengan abnormal return pada $\mathrm{t}_{0}$. Investor lambat bereaksi karena perlunya pertimbangan terlebih dahulu ketika Perppu Nomor 1 Tahun 2017 diterbitkan. Investor membaca dan menganalisis terlebih dahulu isi dari Perppu tersebut sebelum bereaksi untuk melakukan investasi. Abnormal return bernilai negatif (thitung sebesar -2,737) menunjukkan bahwa setelah peristiwa penerbitan Perppu Nomor 1 Tahun 2017, investor menyadari bahwa informasi tersebut bad news. Penerbitan Perppu tersebut akan menimbulkan penarikan dana oleh nasabah besar yang merasa belum melakukan kewajiban perpajakannya, maka nasabah tersebut akan mengalihkan dananya keluar negeri, sehingga terjadinya capital outflow 
yang akan menganggu likuiditas perbankan. Likuiditas perbankan terganggu akan mempengaruhi pembayaran dividen perusahaan perbankan kepada investor.

Hasil penelitian tersebut serupa dengan penelitian dilakukan oleh Wibowo (2017) menyatakan bahwa terdapat abnormal return yang signifikan di sekitar terjadinya peristiwa pengumuman Paket Kebijakan Ekonomi Tahap I Jokowi-JK. Selaras dengan penelitian internasional yang dilakukan oleh Xiao \& Gao (2017) bahwa terdapat abnormal return yang signifikan pada tanggal kejadian proses legislatif Undang-Undang tentang Keamanan Pangan pada industri makanan di China. Penelitian yang dilakukan oleh Makino (2016), meneliti respon pasar saham terhadap kecelakaan kimia di Jepang menghasil abnormal return rata-rata kumulatif negatif secara signifikan setelah terjadinya kecelakaan tersebut.

Pengujian hipotesis dengan one sample t-test apabila sig (2-tailed) $<0,05$ maka terdapat trading volume activity yang signifikan yang dapat diartikan juga ada reaksi pasar terhadap pengumuman penerbitan Perppu Nomor 1 Tahun 2017, begitu pula sebaliknya. Hasil uji trading volume activity di tampilkan sebagai berikut:

Tabel 7.

Hasil Uji One Sample t-test

Trading Volume Activity (TVA)

\begin{tabular}{ccc}
\hline $\begin{array}{c}\text { Periode } \\
\text { Jendela }\end{array}$ & $\begin{array}{c}\text { Signifikansi } \\
\text { (2-tailed) }\end{array}$ & $\begin{array}{c}\text { Keterangan } \\
\text { Trading Volume } \\
\text { Activity }\end{array}$ \\
\hline $\mathbf{- 2}$ & 0,003 & Terdapat \\
$\mathbf{- 1}$ & 0,004 & Terdapat \\
$\mathbf{0}$ & 0,000 & Terdapat \\
$\mathbf{+ 1}$ & 0,001 & Terdapat \\
$\mathbf{+ 2}$ & 0,001 & Terdapat \\
\hline
\end{tabular}

Sumber: Data diolah, 2017 
Hasil pengujian trading volume activity diatas menunjukkan bahwa, sebelum, saat dan setelah penerbitan Perppu Nomor 1 Tahun 2017 pada $\mathrm{t}_{-2}, \mathrm{t}_{-1}, \mathrm{t}_{0}$, $\mathrm{t}_{+1}, \mathrm{t}_{+2}$ terdapat TVA yang signifikan. Hal tersebut menunjukkan nilai signifikansi lebih kecil dari 0,05, maka seluruh periode pengamatan menunjukkan tradimg volume activity yang signifikan. Berdasarkan analisis terhadap reaksi pasar yang diukur dengan trading volume activity, hipotesis kedua yang menyatakan bahwa terdapat trading volume activity yang signifikan di sekitar penerbitan Perppu Nomor 1 Tahun 2017 diterima. Perubahan trading volume activity dapat dilihat pada grafik berikut:

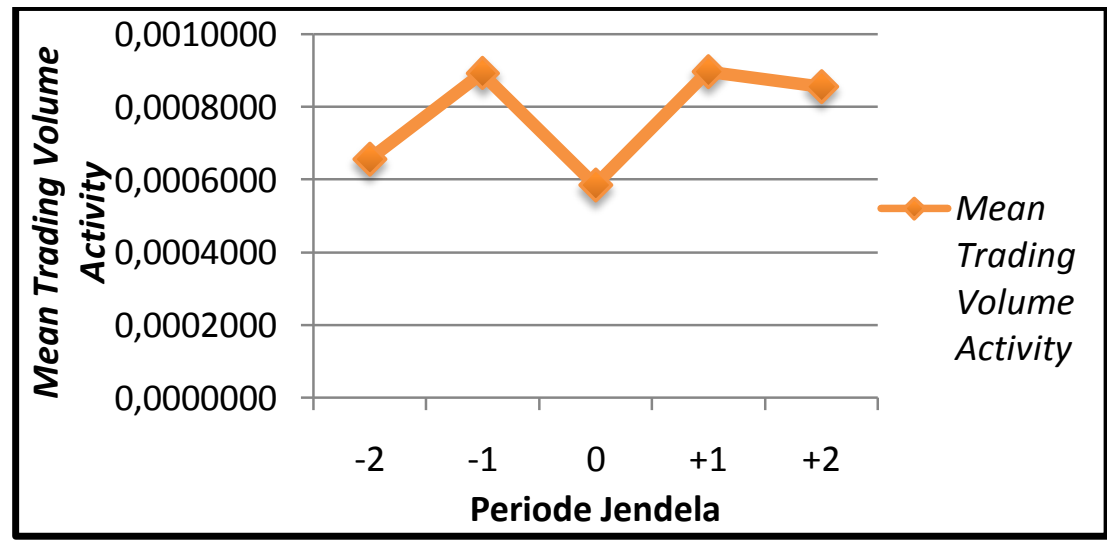

Gambar 5.

Perubahan Rata-Rata Trading Volume Activity

Saham Periode Pengamatan Penerbitan Perppu

Nomor 1 Tahun 2017

Sumber: Data diolah, 2017

Hasil penelitian menyatakan adanya reaksi yang berfluktuatif diukur dengan trading volume activity pada $\mathrm{t}_{-2}, \mathrm{t}_{-1}, \mathrm{t}_{0}, \mathrm{t}_{+1}, \mathrm{t}_{+2}$, artinya reaksi pasar terhadap penerbitan Perppu Nomor 1 Tahun 2017 selalu terjadi. Reaksi terbesar terjadi pada $\mathrm{t}_{0}$ (t-hitung sebesar 4,827), hal ini dikarenakan aksi rebound dari pelaku pasar modal setelah tertahan pada hari-hari sebelumnya. Aksi rebound yaitu dimana harga saham sudah turun dan nantinya akan berubah naik, maka investor 
membeli saham pada saat terjadinya penurunan tersebut dari adanya informasi penerbitan Perppu ini, kemudian menjualnya kembali pada saat harga kembali naik. Setelah pengumuman penerbitan Perppu pada $t_{+1}$ dan $t_{+2}$ mengalami kenaikan dan penurunan TVA, hal ini berarti investor bereaksi sudah tidak berdasarkan pengumuman penerbitan Perppu Nomor 1 Tahun 2017.

Hasil penelitian tersebut sesuai dengan yang dinyatakan oleh penelitian Saputra (2016) yang menemukan trading volume activity yang signifikan pada peristiwa pemilihan umum presiden dan wakil presiden tahun 2014 saham LQ-45. Penelitian Wulandari, dkk. (2017) menemukan trading volume activity yang signifikan setelah terjadinya peristiwa berlakunya undang-undang tax amnesty.

\section{SIMPULAN}

Berdasarkan hasil penelitian yang diperoleh diatas, maka dapat diambil simpulan, yaitu reaksi pasar modal Indonesia terhadap penerbitan Perppu Nomor 1 Tahun 2017 tentang akses informasi keuangan untuk kepentingan perpajakan direaksi pada $\mathrm{t}_{-1}$ dan $\mathrm{t}_{+2}$ yang diukur dengan abnormal return. Reaksi pasar yang diukur dengan trading volume activity direaksi pada $\mathrm{t}_{-2,}, \mathrm{t}_{-1}, \mathrm{t}_{0}, \mathrm{t}_{+1}$ dan $\mathrm{t}_{+2}$.

Berdasarkan hasil penelitian dan simpulan yang telah diperoleh, maka diajukan beberapa saran untuk investor dan calon investor serta manajemen perusahaan perbankan. Bagi investor dan calon investor yang akan berinvestasi, sebaiknya lebih mempertimbangkan dan menganalisis peristiwa penerbitan peraturan pemerintah lainnya dan Perppu Nomor 1 Tahun 2017 saat penerapannya dilakukan pada tahun 2018, sehingga investor dan calon investor dapat mengambil keputusan untuk berinvestasi dan dapat memperoleh keuntungan yang diinginkan. 
Bagi manajemen perusahaan perbankan, agar mengikuti dan mempelajari dengan baik Perppu Nomor 1 Tahun 2017 tentang akses informasi keuangan untuk kepentingan perpajakan agar lebih siap menghadapi penerapan Perppu ini di tahun 2018. Perusahaan perbankan yang lebih siap dan dapat menangani Perppu ini, dampaknya yaitu tata kelola perusahaan akan lebih bagus dan meningkatnya tingkat kepercayaan nasabah kepada perusahaan perbankan.

\section{REFERENSI}

Abuzayed, B. (2013). Sport and Emerging Capital Markets: Market Reaction to The 2022 World Cup Announcement. International Journal of Islamic and Middle Eastern Finance and Management, 6(2), 122-141.

Ang, R. (1997). Buku Pintar Pasar Modal Indonesia. Jakarta: Erlangga.

Asteriou, D., Samitas, A., \& Kenourgios, D. (2013). The London 2012 Olympic Games Announcement and Its Effect on The London Stock Exchange. Journal of Economic Studies, 40(2), 203-221.

Dai, Y., Kong, D., \& Wang, M. (2013). Investor Reactions to Food Safety Incidents: Evidence From the Chinese Milk Industry. Food Policy, 43, 2331 .

Danylchuk, K., Stegink, J., \& Lebel, K. (2016). Doping Scandals in Professional Cycling: Impact on Primary Team Sponsor's Stock Return. International Journal of Sports Marketing and Sponsorship, 17(1), 37-55.

De Souza, H. E., Barbedo, C. H. D. S., \& Araújo, G. S. (2017). Does Investor Attention Affect Trading Volume in The Brazilian Stock Market? Research in International Business and Finance, $I$.

Fama, E. F. (1970). Efficient Capital Markets-A Review of Theory and Empirical Work. The Journal of Finance, 25(2), 383-417.

Fama, E. F. (1991). Efficient Capital Markets: II. The Journal Of Finance, $X L V I(5)$.

Febriyanti, S., \& Rahyuda, H. (2016). Pengaruh Pengumuman Perubahan Harga BBM Awal Pemerintahan Jokowi-JK Terhadap Reaksi Pasar Modal Indonesia. E-Jurnal Manajemen Unud, 5(2), 838-869.

Ghozali, I. (2011). Aplikasi Analisis Multivariate dengan Program IBM SPSS 19 
(5th ed.). Semarang: Badan Penerbit Universitas Diponegoro.

Gul, S., Khan, M. T., Saif, N., Rehman, S. U., \& Roohullah. (2013). Stock Market Reaction to Political Events (Evidence from Pakistan). Journal of Economics and Sustainable Development, 4(1), 2222-1700.

Hachenberg, B., Kiesel, F., Kolaric, S., \& Schiereck, D. (2016). The Impact of Expected Regulatory Changes: The Case of Banks Following The 2016 U.S. Election. Finance Research Letters, 0, 1-6.

Hall, S. G., \& Kenjegaliev, A. (2016). The Effect of Oil Price Changes on The Price of Russian and Chinese Oil Shares. Empirical Economics, 1-18.

Hartono, J. (2015). Teori Portofolio dan Analisis Investasi (Kesepuluh). Yogyakarta: BPFE.

Hidayat, M. T. (2012). Analisis Reaksi Pasar Modal Indonesia Terhadap Peristiwa Non Ekonomi (Studi Kasus Peristiwa Bom JW Mariott/Ritz Carlton 17 Juli 2009). Media Ekonomi \& Teknologi Informasi, 20(2), 16-32.

IHSG. (2017). Retrieved from www.idx.co.id

Indonesia, L. N. R. I. (2017). Peraturan Pemerintah Pengganti Undang-Undang Republik Indonesia Nomor 1 Tahun 2017 Tentang Akses Informasi Keuangan untuk Kepentingan Perpajakan. Retrieved from www.peraturan.go.id

Kementerian Keuangan, R. I. (2017). Revisi Peraturan Menteri Keuangan Nomor 70/PMK.03/2017 tentang Petunjuk Teknis Mengenai Akses Informasi Keuangan Untuk Kepentingan Perpajakan. Retrieved from www.wise.kemenkeu.go.id

Li, P., Tang, H., \& Liao, J. (2016). The Intraday Effect of Nature Disaster and Production Safety Accident Announcement Based on High-Frequency Data From China's Stock Markets. China Finance Review International, 5(3), 277-302.

Makino, R. (2016). Stock Market Responses to Chemical Accidents in Japan: An Event Study. Journal of Loss Prevention in the Process Industries, 44, 453458.

Munawir. (1998). Analisis Laporan Keuangan. Yogyakarta: BPFE.

Pratama, I. G. B., Sinarwati, N. K., \& Dharmawan, N. A. S. (2015). Reaksi Pasar Modal Indonesia Terhadap Peristiwa Politik ( Event Study pada Peristiwa Pelantikan Joko Widodo Sebagai Presiden Republik Indonesia Ke-7). EJournal S1 Akuntansi Universitas Pendidikan Ganesha, 3(1). 
Purba, T. (2017). Analisis Komparasi Abnormal Return dan Volume Perdagangan Saham Atas Pemberlakuan Peraturan Pemerintah Nomor 1 Tahun 2014. Jurnal Riset Dan Manajemen, 5(1), 55-72.

Repousis, S. (2016a). Abnormal Stock Returns in Greece During the Cypriot Banking Crisis. Journal of Money Laundering Control, 19(2), 122-129.

Repousis, S. (2016b). Stocks' Prices Manipulation Around National Elections? An Event Study for The Case of Greek Banking Sector. Journal of Financial Crime, 23(2).

Rosati, P., Cummins, M., Deeney, P., Gogolin, F., van der Werff, L., \& Lynn, T. (2017). The Effect of Data Breach Announcements Beyond The Stock Price: Empirical Evidence on Market Activity. International Review of Financial Analysis, 49, 146-154.

Rossiana, G., \& Muslim, A. (2017). Perppu Akses Keuangan Tak Ganggu Kinerja Bank. Retrieved from www.beritasatu.com

Sanjiwani, P. D. A., \& Jati, I. K. J. (2017). Reaksi Pasar Modal Terhadap Kebijakan Tax Amnesty pada Saat Pengumuman dan Akhir Periode I. EJurnal Akuntansi Universitas Udayana, 19(1), 799-826.

Saputra, I. (2016). Analisis Perbedaan Rata-Rata Trading Volume Activity Saham Sebelum Dan Sesudah Pemilu Presiden dan Wakil Presiden Tahun 2014 (Event Study pada Saham LQ-45 di Bursa Efek Indonesia Periode 29 Juni-19 Juli 2014). Jurnal Ekonomi Dan Bisnis, 9(1), 76-86.

Sari, N. P. T. P., Purnamawati, I. G. A., \& Herawati, N. T. (2017). Analisis Komparatif Saham LQ45 Sebelum dan Sesudah Pilpres Amerika Serikat 2016. E-Journal S1 Akuntansi Universitas Pendidikan Ganesha, 1(1).

Sudewa P, D. G. O., \& Sari, M. M. R. (2015). Reaksi Pasar Atas Peristiwa Pilpres 2014. E-Jurnal Akuntansi Universitas Udayana, 12(3), 465-480.

Sugiyono. (2013). Metode Penelitian Bisnis. Bandung: Alfabeta.

Tandelilin, E. (2010). Portofolio dan Investasi (Pertama). Yogyakarta: Kanisius.

Towoliu, W. P. (2013). Fungsi Lembaga Perbankan dalam Melindungi Nasabah Melalui Aspek Kerahasiaan Bank, 1(2), 11-24.

Vikash, H. N. A. P., Moosa, R. I., \& Nguyen, J. H. (2017). The Effects of Regulatory Announcement on Risk and Return: The Vietnamese. Pacific Accounting Review, 29(2). 
Wibowo, A. (2017). Reaksi Investor Pasar Modal Indonesia Terhadap Paket Kebijakan Ekonomi Tahap I Jokowi-JK (Studi pada Saham LQ45 Periode Agustus 2015-Pebruari 2016). Media Ekonomi Dan Manajemen, 32(1), 5967.

Wulandari, I. G. A. A. D., Wahyuni, M. A., \& Sujana, E. (2017). Reaksi Investor Dalam Pasar Modal Terhadap Undang-Undang Tax Amnesty (Event Study Pada Perusahaan yang Terdaftar Dalam LQ45 di Bursa Efek Indonesia). EJournal S1 Akuntansi Universitas Pendidikan Ganesha, 7(1), 10-19.

Xiao, X., \& Gao, Y. (2017). An Event Study of The Effects of Regulatory Changes on The Food Industry. China Agricultural Economic Review, 9(1), 81-92.

Yuniati, T. (2017). Analisis Abnormal Return dan Trading Volume Activity Saham LQ45 pada Seputar Peristiwa Pengumuman Kebijakan Pengampunan Pajak (Tax Amnesty). Skripsi, (Universitas Lampung, Bandar Lampung).

Yuwono, A. (2013). Reaksi Pasar Modal di Bursa Efek Indonesia Terhadap Pengumuman Peristiwa Bencana Banjir yang Melanda Daerah Khusus Ibu Kota Jakarta 2013. Jurnal Nominal, II(II).

Zhang, Y., Wan, D., \& Fu, L. (2013). Impact of Media on Stock Returns: An Indepth Empirical Study in China. Chinese Management Studies, 7(4), 586603. 